\title{
LA RENOVACIÓN DE LA CULTURA ESPAÑOLA A TRAVÉS DEL PENSAMIENTO ALEMÁN: KRAUSE Y EL KRAUSISMO
}

\section{Gonzalo Capellán de Miguel ${ }^{*}$}

\section{La renovación de la cultura española a través del pensamiento alemán: Krause y el krausismo'}

En este artículo se pretende poner de manifiesto el destacado papel que la corriente de pensamiento del krausismo español desempeñó en la apertura y enriquecimiento de la cultura en nuestro país durante la segunda mitad del siglo pasado. Para ello hemos creído conveniente estructurar su contenido en torno a cuatro puntos fundamentales.

En primer lugar haremos referencia al pensamiento de Krause y al de sus discípulos que más influyeron en la filosofía krausista de nuestro país: Ahrens y Tiberghien. Será una buena ocasión para que podamos saber algo más sobre dos personajes tan desconocidos para nuestra cultura, a pesar del trascendental papel que en su progreso desempeñaron. Es preciso advertir desde este instante que vamos a hacer bascular, de forma quizá desproporcionada, nuestra exposición teórica sobre este punto. Ello es así debido a la identidad básica entre el pensamiento de Krause, Ahrens y Tiberghien y el de los krausistas españoles, de manera que un conocimiento adecuado del primero permite abordar el segundo sin abundar en detalles. ${ }^{2}$ Lo hemos creído más interesante por la facilidad con que se puede acceder al pensamiento de los krausistas españoles, mientras que resulta más complicado hacerlo -por cuestión de accesibilidad a fuentes, así como de inexistencia de bibliografía secundaria al respecto- en el caso de los pensadores a que he aludido.

* Becario de Investigación (FPI), Universidad de Cantabria, Departamento de Historia Moderna y Contemporánea.

1. El presente texto - con la necesaria adaptación formal-procede de una conferencia pronunciada en la Universidad de Cantabria el 13 mayo de 1997.

2. Véase el trabajo de investigación presentado por el autor en la Universidad de Cantabria en Junio de 1997, El origen alemán del krausismo: repercusiones sobre la cultura española del siglo XIX (inédito). 
En un segundo momento nos ocuparemos del krausismo español propiamente dicho. Sin entrar en casos particulares (lo cual resultaría enormemente prol ijo), expondremos su pensamiento en los planos ético y educativo, que son los que mejor definen a nuestro krausismo y que completan la parte filosófica (Krause), jurídico-política (Ahrens) y religiosa (Tiberghien) tratadas en el apartado primero.

A continuación haremos una breve alusión a las otras manifestaciones principales de la vida cultural española de la segunda mitad del siglo XIX, pero especialmente al pensamiento tradicionalista y neotomista que lleva a cabo la crítica más mordaz contra el krausismo.

Finalmente, analizaremos la visión que del fenómeno krausista nos ha presentado la historiografía contemporánea y las revisiones necesarias que de la misma deben efectuarse a la luz del conocimiento actual sobre la materia, así como una evaluación final del sentido profundo del krausismo español.

Planteada la cuestión y esbozado su esquema de presentación podemos ya iniciar su desarrollo.

\section{I.1. K.Ch.F. Krause: contexto filosófico y teoría del conocimiento}

Hemos de comenzar indicando que el krausismo es la corriente de pensamiento que se desarrolla en España desde los años cuarenta del pasado siglo hasta la tercera década, aproximadamente, del actual y que se inspira en la filosofía de K.F.Ch. Krause. ${ }^{3}$ Krause (que no "Kraus" como aún se decía a principios de los años 80 en nuestro país en un programa que la segunda cadena de RTVE dedicaba al krausismo español $)^{4}$ ha sido el gran desconocido de la hi storia de la filosofía española hasta fechas muy recientes (prácticamente comienzos de los 90). Esta omisión es más comprensible en la historia de la filosofía europea o universal -en la que Krause ocupó, ciertamente, un lugar secundario ${ }^{5}$,

3. Ha habido diferentes posiciones entre la historiografía sobre el krausismo con respecto a la extensión cronológica de esta corriente cultural. Si bien su inicio tiende a situarse a principios de los años cuarenta con la traducción del Curso de Derecho Natural de Ahrens por Ruperto Navarro Zamorano en 1841 (cfr.M.Andrino Fernández, "Navarro Zamorano y los orígenes del krausismo español", en Revista de Estudios Políticos, núm.53, sept-oct. 1986, pp. 71-100) o con el famoso viaje de Sanz del Río a Alemania en 1843 (cfr.M.T.Rodríguez de Lecea, Antropología y Filosofía de la Historia en Julián Sanz del Río. Madrid, CEC, 1991), su final ha sido ubicado por J.López Morillas (El krausismo español. El perfil de una aventura intelectual. México. F.C.E. 1980) con la irrupción del positivismo a partir de 1875, prolongado por E. Díaz (La filosofía social del krausismo español. Valencia, Fernando-Torres editor, 1983) hasta la II República a través de institucionistas como Julián Besteiro o Fernando de los Ríos, y extendido hasta mucho después por A.Heredia Soriano ("El krausismo español", en VV.AA., Cuatro ensayos de historia de España. Madrid, Cuadernos para el Diálogo, 1975).

4. J.A.Silva, El krausismo en España. Madrid, RTVE, 1980 (50 aprox.).

5. Su figura se encuentra ausente de obras tan importantes como la Historia de la Filosofía de F.Copleston (Barcelona, Ariel, 1984), que ni siquiera hace alusión a Krause a lo largo de las casi 400 páginas que componen su volumen VII, "De Fichte a Nietzsche". 
pero resulta menos disculpable en la española, en la cual representa un momento muy importante. Sin embargo, sabemos hoy bastante sobre su vida y obra. ${ }^{6}$

Nacido en 1781 en Eisenberg, estudió en la Universidad de Jena entre 1797 y 1801. Allí recibió clases de Fichte y Schelling, principales representantes del idealismo alemán. Krause sería igualmente coetáneo del otro gran filósofo del momento: Hegel. Tras licenciarse en teología y matemáticas comenzó su periplo como Privatdozen por las Universidades alemanas: Jena (1802-4), Berlín (1814) y Gottinga (1823-1831). ${ }^{7}$ Un año más tarde moría en Munich. Merece la pena apuntar además que Krause fue militante activo de la masonería en Dresden (logia "Las tres espadas y verdaderos amigos") entre 1805 y 1810 en que fue definitivamente expulsado por sus intentos de reformar la institución rompiendo con su secretismo tradicional, experiencia que marcaría buena parte de su vida y de su obra. ${ }^{8}$

Lo realmente importante de este breve apunte biográfico es que Krause desarrolló su labor intelectual en el momento de máximo apogeo de la filosofía idealista alemana, a cuya influencia no podría escapar pese a su reacción contra el idealismo absoluto de sus maestros. ${ }^{9}$ Es precisamente ese contexto histórico el que mejor nos puede hacer comprender la principal característica del pensamiento krausiano: la armonía o el intento conciliador de toda posición extrema en cualquier ámbito de la vida. Concepción que revestirá la forma de organicismo: las partes, la variedad, lo individual, pueden coexistir en el todo, en la unidad, en lo común.

Desde el punto de vista filosófico, el idealismo alemán venía a culminar la tendencia espiritualista iniciada en la época moderna con la res cogitans de Descartes. Para Hegel la realidad y la historia no eran sino el desarrollo en el tiempo de la Idea, de lo Absoluto, del Ser a medida que este va tomando conciencia de sí mismo (autoconciencia). Una tendencia totalmente opuesta que destacaba la realidad exterior, empírica, como lo único verdadero se había

6. Especialmente gracias al amplio y magnífico estudio biográfico del profesor E.Menéndez Ureña, Krause educador de la humanidad. Una biografía. Madrid, Unión Editorial, 1991. También resulta fundamental el amplio estudio preliminar de R.V.Orden Jiménez a Las habilitaiones filosóficas de Krause Madrid, UPCO, 1996.

7. Vid. la evolución de su filosofía en estos estadios en el citado "Estudio preliminar" de R.V.Orden Jiménez.

8. Sobre la relación del krausismo con la masonería pueden verse los trabajos del profesor P.Álvarez Lazaro, "La Institución Libre de Enseñanza y el universalismo masónico europeo", en Revista de Occidente, núm.101, octubre 1989, pp. 88-106 y La masonería esuela de formación del ciudadano. (La educación interna de los masones españoles en el último tercio del siglo XIX) Madrid, UPCO, 1995.

9. Para Krause y sus discípulos la filosofía idealista reposaba sobre la "Sintética" y era por tanto meramente hipotética. De ahí que el krausismo desarrollara con especial énfasis la parte "Analítica" (y por ello la Psicología, los "hechos internos") del "Sistema" como fundamento inductivo de la deducción (cfr. H.Ahrens, Curso de Psicología, p.197 y Curso de Filosofía, pp. 145 y 200; ambas traducidas por Gabino Lizárraga y publicadas por Victoriano Suárez en Madrid en 1873). 
desarrollado paralelamente, sobre todo en Inglaterra, y había ejercido gran influencia en el continente a través del sensualismo de Condillac. Frente a ambos extremos, y sin rechazar nunca la verdad parcial contenida en cada uno de esos sistemas (contra todo exclusivismo), Krause trató de construir una síntesis superadora de ambos que concediera igual dignidad a lo espiritual y a lo material.

La consecuencia de semejante planteamiento para la epistemología iba a ser determinante. Para Krause la teoría del conocimiento no puede desconocer ni la observación, los hechos, ni la especulación, las ideas. Antes bien, debe componerse de una adecuada combinación de ambas. ${ }^{10}$ De aquí nace la teoría del "Ideal", noción clave de su filosofía. El Ideal expresa lo que debe ser de acuerdo con la razón, con el orden divino de la vida, mientras que los hechos muestran la realidad, lo que es. De explicitar lo primero se encarga la Filosofía, de lo segundo la Historia y todas las ciencias constan de ambas partes. Finalmente, existe una tercera ciencia que se ocupa de transformar la realidad para adecuarla, progresivamente y de forma pacífica al Ideal. En esa adaptación consiste precisamente el progreso que es el fin del hombre (influencia del Aüfklarung). Esta labor corresponde a la Política o ciencia de las reformas. Es en este punto, en la dimensión práctica que debe adoptar toda filosofía, donde Krause se distancia de los sistemas especulativos de sus colegas del idealismo alemán encaminándose por la senda que luego Marx haría celebre en su tesis $\mathrm{XI}$ sobre Feuerbach (conocer el mundo-transformarlo) y que era, en realidad, una crítica al idealismo de Hegel. ${ }^{11}$

\subsection{Ahrens: teoría del Estado y de la sociedad}

Para avanzar en el conocimiento de la filosofía de Krause y por no caer en una exposición monográfica del autor, nos acercaremos a su teoría jurídica por medio de Heinrich Julius Ahrens (1808-1874), discípulo de Krause en Gotinga, de donde fue expulsado, junto con su maestro, por una revuelta acaecida en 1831. Ese acontecimiento propiciaría la oportunidad para que la filosofía de Krause comenzara su difusión más allá de las fronteras alemanas porque Ahrens se dirigiría a Bélgica y allí recibió la invitación de Guizot para dar un curso de psicología en la Universidad de París entre 1833 y $1834 .{ }^{12}$ Fue allí también don-

10. Esta consideración implica una adecuada revisión de la relación existente entre krausismo y positivismo en España durante el último cuarto del siglo pasado. En este sentido escribimos recientemente el artículo (de pronta aparición) "El krausismo español: entre idealismo y positivismo. Algunas reflexiones sobre el concepto de krausopositivismo". (num. de 1998 del Boletín de la Biblioteca Menéndez Pelayo).

11. G. Bueno ha puesto de relieve estos aspectos en su artículo "Krausismo y marxismo (en torno al Krause de E. M. Ureña)", en El Basilisco, núm. 10, 1991, pp. 89-98. Allí diferencia el conocido filósofo entre una filosofía teóricamente implantada (bios theoretikós) y otra politicamente (bios politikós). Mientras que el idealista sería un homo theoreticus, el krausista lo sería politicus.

12. La iniciativa partió de V. Cousin, lo cual no es de extrañar dada la similitud entre eclecticismo espiritualista y krausismo (ya señaladas en El origen alemán..., op.cit., 74-77). El eclec- 
de muchos exilados españoles y latinoamericanos tomaron contacto por primera vez con la filosofía de Krause, que Ahrens difundió no sólo de forma más clara, sino, además, en una lengua más accesible para el mundo latino, la fra ncesa, bien conocida entre las elites intelectuales españolas. ${ }^{13} \mathrm{Al}$ final de ese año Ahrens regresó a Bélgica, donde se le otorgó una plaza de profesor en la recién creada Universidad Libre de Bruselas (liberal y masónica). ${ }^{14}$

Ahrens diseminaría las semillas del krausismo a través de su teoría jurídica, expuesta básicamente en su Curso de Derecho Natural (1838). Su contenido esencial nos ofrece una teoría del Estado como la institución especial para el derecho cuya actividad no debe salirse de los límites que esa esfera propia le impone. El resultado es el rechazo manifiesto de todo absolutismo estatal. La tutela que en los tiempos modernos ha ejercido sobre otras esferas de la vida como la educación, la ciencia o la religión ha sido fruto del imperfecto desarrollo histórico que no las ha dotado de las instituciones apropiadas para su desarrollo autónomo, pero debe desaparecer definitivamente. Se trata, por tanto, de un modelo del Estado más bien abstencionista, en el que su misión reside únicamente en proporcionar los medios necesarios a las demás esferas para que cumplan con sus fines. Sólo de ese modo podrá cada individuo realizar su destino. De otra forma eso sería imposible porque el hombre es, por natural eza, un ser social y nada puede aislado. ${ }^{15}$ De ahí que Ahrens sea partidario del fomento del asociacionismo, de la creación de cuerpos intermedios entre individuo y Estado que permitan al hombre lograr sus fines vitales. Consecuente con esos planteamientos, Ahrens propone un modelo político constitucional (monárquico) y parlamentario, en el que la representación se efectúe de forma corporativa, es decir, una democracia orgánica como la sociedad misma. La sociedad no es un mero agregado de individuos (concepción atomística) sino un organismo (holista). Por la misma razón su representación no debe proceder

ticismo francés de $V$. Cousin fue el soporte ideológico de la Monarquía de Orleans surgida de la Revolución de Julio -1830- (cfr. L. Díez del Corral, El liberalismo doctrinario, Instituto de Estudios Políticos, 1973, p. 47) y dominaría en la enseñanza oficial francesa hasta casi finales de siglo (cfr. W. Logue, From Philosophy to Sociology. The evolution of French Liberalism, 1870-1914, Dekalb, Illinois, 1983, p. 17) y la de nuestro país durante el período isabelino (cfr. A. Heredia Soriano, Política docente y filosofía oficial en la España del siglo XIX. La era isabelina (18341868), Universidad de Salamanca, 1982, pp. 413 y 416).

13. No así el alemán como lo demuestra el hecho de la publicación en 1844 de la Gramática alemana de Julio Kühn (en colaboración con Sanz del Río) con el fin de hacer accesible la cultura alemana a los estudiosos españoles (cfr. E. Terrón, Textos escogidos. Sanz del Río. Barcelona, Ediciones de Cultura Popular, 1968, p.65).

14. Cfr. S. Monreal, "Krausistas y masones: un proyecto educativo común. El caso belga", en Historia de la Educación. Revista Interuniversitaria, Salamanca, núm. 9, 1990, pp. 63-70.

15. Cfr. Curso completo de derecho natural o filosofía del derecho con arreglo al estado actual de esta ciencia en Alemania. Madrid, Imprenta de Baylli-Bailliere, 1864, pp. 7 y 53.

16. Cfr. su Enciclopedia Jurídica o exposición orgánica de la ciencia del derecho y el Estado. Madrid, Librería de Victoriano Suárez,1878-80, t. III, pp. 331-336. 
del sufragio individual, sino de la elección corporativa, por órganos sociales. ${ }^{16}$ Todo ello está plenamente de acuerdo con el liberalismo social que Ahrens defiende frente al de corte individualista dominate hasta la revolución del 48.

\section{I.3. G.Tiberghien: la religión krausista}

Para dar un nuevo paso en la filosofía krausista es preciso que nos desplacemos ahora hasta la continuación de la labor de Ahrens en Bruselas a través de su discípulo G.Tiberghien (1819-1901). Este filósofo Belga tuvo una larga y briIlante vida académica (hasta finales de siglo en la ULB, donde fue rector en varias ocasiones $y$, durante las décadas centrales del XIX, su figura más emblemática) que supo compaginar con la política (partido liberal). Como su maestro, se mostrará fiel seguidor de Krause, cuya filosofía determinó su obra desde sus precoces comienzos en los años 40 hasta el final de sus días..$^{17}$ La influencia de Tiberghien en nuestro país se produciría principalmente gracias a sus enseñanzas en materia de moral y religión. Durante el "Sexenio revolucionario" muchas de sus obras serían traducidas a nuestra lengua y despertarían las críticas de Ios sectores más reaccionarios del catolicismo. Tiberghien sabía perfectamente lo que suponía vivir en un país predominantemente católico. Como Krause, Tiberghien nunca rechazó la religión ${ }^{18}$ y de hecho su filosofía pudiera calificarse $\sin$ temor de teísmo, eso sí racional. El sistema krausiano estaba coronado por Dios (Wessen), pero no se trataba del Dios tradicional del catolicismo. Era el Ser absoluto e infinito al que se llegaba no por la fe, sino por la razón. Tiberghien defendió siempre la libertad de pensamiento como derecho imprescriptible del individuo. ${ }^{19}$ Una de las principales consecuencias de ello era la libertad de conciencia y, por tanto, de culto, pero la Iglesia no estaba dispuesta a aceptarlo.

Tiberghien hizo del dogmatismo eclesiástico encarnado en su etapa medieval el principal flanco de sus ataques a la Iglesia. ${ }^{20}$ La autoridad y la intolerancia debían dejar paso al razonamiento propio y a la tolerancia. Religión y ciencia, fe y razón no eran términos antitéticos imposibles de reconciliar. Apli-

17. Cfr. el artículo de $H$. Hasquin "G. Tiberghien, discípulo de Krause: librepensamiento y teísmo en la Bélgica del siglo XIX", en P.Alvárez Lázaro (ed.), Librepensamiento y secularización en la Europa contemporánea. Madrid, UPCO, 1996, pp. 129-73.

18. Distinguió entre Religión y religiones (diferentes credos positivos conocidos a lo largo de la historia de los que el catolicismo no es sino uno más). Aunque fue contrario a las segundas, siempre consideró la primera como connatural al hombre y, por lo tanto, necesaria. Esta concepción prevaleció entre los krausistas españoles todavía a principios del presente siglo, como muestra la conferencia pronunciada por G. de Azcárate en Bilbao en 1909 con el significativo título de "La Religión y las religiones".

19. Cfr. J. Bartier, "Franc-Maçonnerie, libre examen et athéisme. Relations historiques entre I'ULB, l'atheisme et le Libre examen", en Laïcité et franc-maçonnerie. Bruselas, 1982, pp. 343-350.

20. Cfr. sus Estudios sobre religión. Madrid, Imprenta de Manuel G. Hernández, 1873, pp. 22 y 25. La misma posición se puede observar en el prólogo que le precede, obra del destacado krausista y republicano español Nicolás de Salmerón. 
cando la dialéctica armónica de Krause, Tiberghien creía sinceramente en su mutua compatibilidad. ${ }^{21}$

Su modelo religioso consistía básicamente en una vuelta al cristianismo primitivo, basado en la doctrina moral de Jesús, que se fundamenta en el amor y la caridad y que reconoce la dignidad de todos los hombres. De hecho, todo el pensamiento krausiano arranca del principio bíblico de semejanza entre Dios y el hombre, pero se le dota de un significado bastante diferente. ${ }^{22}$ Buscando siempre ese difícil equilibrio entre posturas extremas, Krause había creado el concepto de panenteísmo. Como explica Tiberghien, con él se quieren distanciar, por un lado de los panteístas que identifican a Dios con el mundo (todo es Dios) de manera que anulan al individuo. Pero, por otro lado, tampoco acepta el dualismo cristiano que introduce un abismo insuperable entre Dios (infinito) y el hombre (finito). ${ }^{23}$ De esa forma el ser humano sólo puede ampararse en la fe y no puede llegar con su propio entendimiento a Dios; pero entonces tampoco puede amarle y tener fe. El hombre participa de la esencia divina a través de la razón, que le distingue de los demás seres del universo. Por ella conoce a Dios y le ama. Así podrá perfeccionarse moralmente actuando de acuerdo con su razón y llegar un día a la verdadera religión, unión con Dios (Gottininkeit). ${ }^{24}$

\section{El krausismo español: la ética y la pedagogía}

El corpus teórico descrito sería el que diera nacimiento al krausismo español, es decir, la recepción de la filosofía de Krause en nuestro país, que se produjo por dos vías principales. En primer lugar, por la traducción que del Curso de Derecho Natural de Ahrens realizara Ruperto Navarro Zamorano en $1841 .{ }^{25}$

21. Los Conflictos entre la ciencia y la religión como rezaba la popular obra de Draper eran una cuestión candente en la segunda mitad del siglo pasado (en España especialemnte durante los años 70 del mismo). La posición de Krause y los krausistas queda perfectamente reflejada en una serie de artículos que el destacado krausista alemán $\mathrm{H}$. de Leonhardi publicara en el Boletín Revista de la Universidad de Madrid a lo largo de 1870 bajo el título de "Religión y Ciencia". Un interesante comentario actual sobre la cuestión puede encontrarse en el cápitulo que Gustavo Bueno le dedica en sus Cuestiones cuodlibetales sobre Dios y la religión. Madrid, Mondadori España, 1989.

22. Así aparece expresado, por ejemplo, en el Ideal de la Humanidad para la vida de Krause, traducido por Sanz del Río. Madrid, Imprenta de F.Martínez Garcia, 1871, (2ª ed.), pp. 75-76, 92 y 243.

23. Véase su Introducción a la filosofía y preparación a la metafísica. Estudio analítico sobre los objetos fundamentales de la ciencia. Crítica del positivismo. Madrid, Imprenta de la Revista de Legislación, 1875, pp. 390-1.

24. Este y muchos otros aspectos sobre la cuestión han sido más ampliamente desarrollados en nuestro artículo "El krausismo belga. La filosofía práctica de G.Tiberghien", en Edades, Santander, núm. 2, diciembre 1997, pp. 63-84.

25. Hubo ediciones y reimpresiones españolas posteriores en 1864, 1873, 1876, 1880, 1887,1890 y 1906 . Para una aproximación a la trascendencia de esta obra para el krausismo puede verse el artículo de A.Jiménez García "Los orígenes del krausismo en España: `El Curso de Derecho Natural' de Ahrens", en Aporía, Núms. 13-14, 1981, pp. 77-107. 
No es esta una cuestión baladí si tenemos en cuenta la importancia del derecho en la formación de la minoría intelectual de la que durante el siglo XIX se extraía la clase dirigente del país. Existe constancia documental sobre el notable influjo del Curso de Ahrens, y de los manuales de derecho de la Universidad española basados en él, en destacados políticos de nuestro país hasta principios de este siglo. ${ }^{26}$ Por último, y más importante aún, por el viaje que Sanz del Rió realizó a Alemania en 1843 y que le puso en contacto con los principales discípulos de Krause en la Universidad de Heidelberg. Tras dicho viaje Sanz del Río se retira a Illescas durante todo un decenio para seguir profundizando en el sistema krausiano, para en los años 50 darlo definitivamente a conocer, tanto desde la cátedra en la Universidad Central de Madrid, como entre sus amigos en las tertulias de la calle Cañizares. ${ }^{27}$ En este sentido el discurso de apertura del curso académico de 1857/8 marca un hito en la difusión del krausismo en nuestro país. ${ }^{28}$ Otro probablemente lo sea la publicación del Ideal de la Humanidad para la vida en $1860 .{ }^{29} \mathrm{En}$ el se expone la teoría social de Krause, de notables tintes masónicos (y utópicos) ${ }^{30}$, puesto que ve el futuro de la Humanidad como una Alianza fraternal de todos los hombres. Hay que destacar que en ella se incluyen los "Mandamientos de la Humanidad" (de Krause) que venían a representar el "catecismo laico" de la moral krausista. Esta se basaba en la realización desinteresada del bien por el mero hecho del bien, sin mirar los fines egoístas o utilitarios del hombre ni la recompensa futura (el cielo). Este hecho es de importancia porque el rasgo definitorio por excelencia de los krausistas españoles será el rigor ético con que regirán sus vidas. ${ }^{31}$ Este aspecto está en relación directa con la otra gran característica de nuestro krausismo: su énfasis en la educación. Fruto de esa concepción moral de la vida -que sale incluso de la esfera interna y de la sagrada conciencia a la que rin-

26. Es el caso de A. Maura como ha señalado recientemente M. J. González en El universo conservador de Antonio Maura. Biografía y proyecto de Estado. Madrid, Biblioteca Nueva, 1997, p. 10.

27. Para un breve relato de estas circunstancias puede consultarse el ya clásico artículo de J. Xirau., "Julián Sanz del Río y el krausismo español", en Cuadernos americanos. Núm. 16, julio-agosto 1944, pp. 55-71.

28. Existe una versión moderna a cargo de A. Jiménez García (Madrid, Excerpta Philosophica, 1996). Su repercusión puede comprobarse en la correspondencia a que el citado discurso dio entre Sanz del Río y otros relevantes personajes del momento (cfr. P. de Azcárate, Sanz del Río (1814-1869). Documentos, Diario y Epistolario. Madrid, Tecnos, 1969, pp. 91-98).

29. La obra, incluida en el Índice por la Iglesia Católica, fue considerada por Fernando de los Ríos como "libro de horas de los krausistas" (citado en A. Jiménez Landi, La Institución Libre de Enseñanza y su ambiente. Madrid, 1996, vol. I., p. 57).

30. Cfr. A. Jiménez García, "Lo utópico en el Ideal de la Humanidad para la Vida de Sanz del Río", en A. Heredia Soriano (coord.), Actas del I Seminario de Historia de la Filosofía Española. Salamanca, 1978, pp. 223-233.

31. Esa es la razón por la cual-según J. L. Calvo Buezas- Ortí y Lara denominó en su momento "textos vivos" a los krausistas suscitando una enorme polémica al respecto (véase su artículo "Luces y sombras del krausismo español", en El Basilisco, núm. 3, 1978, p. 59). 
dieron culto, para anegar al derecho mismo (identificación Moral-Derecho)_-32 es la idea de que toda reforma de la sociedad moderna debe partir de una reforma más profunda, la del propio individuo. El resultado sería el "hombre nuevo" y para ello era preciso desarrollar los modernos métodos pedagógicos inspirados por Krause y desarrollados por Froebel: la formación integral del individuo. ${ }^{33}$ Esta imagen es la que se recoge en el Amigo Manso, una de las novelas en que Galdós lleva a cabo el retrato literario de los krausistas. ${ }^{34} \mathrm{La}$ línea pedagógica del krausismo, fruto de su elitismo intelectualista, se prolongaría con el institucionismo y sus figuras más representativas fueron F. Giner de los Ríos y M. Bartolomé Cossío. ${ }^{35}$

Queda de este modo retratada, en lo esencial, la ideología del krausismo español que podíamos definir como liberal y progresista, pero moderada antes que radical; social y organicista, antes que individualista; reformista antes que revolucionaria; intelectualista (no olvidar que son una minoría, una "elite": la intelligentsia ${ }^{36}$ y moralista. Ideas que fueron calando entre la juventud que se formaba en las aulas de la Universidad de la capital española en los años $6 \mathbf{0}$, gente como N. Salmerón, G. de Azcárate, F. de Paula Canalejas, S. Moret, M. de la Revilla etc., todos ellos influyentes hombres de la vida pública española en los años venideros.

\section{La crítica del tradicionalismo católico al krausismo}

Pues bien, la apuntada naturaleza de su pensamiento así como su progresiva aceptación, que comenzaba a revestir cierta importancia, fue la responsable de que enseguida los sectores más radicales del conservadurismo español sintieran esa amenaza y reaccionaran inmediatamente tratando de desprestigiar al krausismo. Los sectores más integristas del tradicionalismo fueron los principales encargados de llevar a cabo esa crítica. Ello era lógico si tenemos en cuenta que al krausismo se le identificaba en el plano político con el liberalismo (con-

32. Cfr. vgr. M. Rivacoba y Rivacoba, Krausismo y derecho. Santa Fe, Castellvi, 1963, p. 63, nota 41; E. Díaz, op.cit., p. 66 y M.C. Roldán, Los derechos fundamentales en la cultura jurídica española: neotomismo y krausismo. Madrid, Universidad Complutense, 1991, p. 304.

33. Algunos detalles sobre estos aspectos en E. M. Ureña, "Orígenes del krausofröbelismo y massonería", en Historia de la Educación. Revista Interuniversitaria, Salamanca, núm. 9, 1990, pp. 43-61.

34. Sobre la relación entre krausismo y literatura véase el trabajo de E.M. de Jongh-Rossel, El krausismo y la generación de 1898. Valencia-Chapel Hill, Hispanófila Ediciciones, 1985.

35. Una relación entre ambos fenómenos puede encontrarse en A. Jiménez García, El krausismo y la Institución Libre de Enseñanza. Madrid, Cincel, 1985. Para la segunda resultan imprescindeibles los cuatro volúmenes de la magna obra -ya citada- de Jiménez Landi.

36. Aspecto fundamental para una comprensión del krausismo en su conjunto y que fue muy pronto y perspicazmente apuntado por el profesor Vicente Cacho en su clásico, La Institución Libre de Enseñanza. I. Orígenes y etapa universitaria (18 -1881). Madrid, Rialp, 1962, p. 201, por ejemplo. 
denado en el Syllabus de Pío IX), ${ }^{37}$ considerándolo responsable directo de la revolución de 1868; en el religioso con anticatolicismo; ${ }^{38}$ y en el plano social con la secularización de la enseñanza, que socavaba de forma manifiesta los resortes fundamentales del poder de la Iglesia. Nunca está de más volver a citar a Gil de Zárate en su esclarecedor análisis de la importancia del control educativo:

"La cuestión de enseñanza es cuestión de poder: el que enseña, domina; puesto que enseñar es formar hombres, y hombres amoldados a las miras de quien los adoctrina". ${ }^{39}$

No fue, por tanto, por mero capricho o fruto del azar que durante los años 60 el diario integrista El Pensamiento español, a través de las afiladas plumas de Navarro Villoslada y Ortí y Lara, desplegará una feroz campaña de crítica al krausismo. Entre 1864 y 1866 más de una docena de artículos fueron destinados a condenar el panteísmo krausista. ${ }^{40}$ Esta crítica fue la misma que repitió Ortí y Lara tanto en su opúsculo Los discípulos de Krause convictos de panteísmo (1864) como en sus Lecciones sobre el sistema panteísta de Krause (1865), ambos publicados por la imprenta de Tejado. Ya antes había recogido este autor (catedrático en la Universidad Central) el guante del catolicismo, ofendido por el discurso de Sanz del Río en 1857, para impugnarlo y se consolidaría como el adalid de la defensa de la Iglesia frente al krausismo en este período. Su filosofía era muy simple por lo demás. La Iglesia es la legitima administradora y supervisora de la enseñanza porque jesús así se lo dejó encargado a sus apóstoles: docete omnes gentes. ${ }^{41} \mathrm{Y}$ en el caso de la ciencia debe atenerse a lo que dice la doctrina católica, única verdadera, y subordinar la razón a la fe. El modelo de sociedad de los pensadores tradicionalistas no era la civilización moderna que proclamaban los krausistas, sino la de nuestro glorioso pasado nacional del que la unidad católica y la monarquía eran los símbolos más

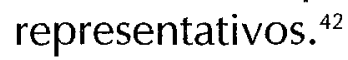

37. El director de la Revista Popular, Sardá Salvany publicó un opúsculo con el significativo título de El liberalismo es pecado, que se convertiría en la "Biblia del integrismo" (cfr. S. HibbsLissorgues, Iglesia, prensa y sociedad en España (1868-1904). Alicante, 1995 p. 135 y nota 31).

38. Véase al respecto la obra de J. Ortí y Jové, El catolicismo y el krausismo o sea el catolicismo y la ciencia acatólica contemporánea. Madrid, Imprenta de Álvarez Hermanos, 1876 y 1884.

39. Citado en V. Cacho, op. cit., p. 40. Esa idea clave la había encontrado (formulada de manera muy similar) ya Gil de Zárate en el Duque de Rivas (véase el primer volumen de su estudio De la Instrucción Publica en España, Oviedo, Pentalfa Ediciones, 1995, pp. 152-3).

40. Destacan los referidos al krausismo como panteísmo que Navarro Villoslada (director del períodico) escribiera el 26 de febrero y los días $7,10,17,18$ y 19 de marzo de 1864.

41. Cfr. "Las cinco llagas de la enseñanza pública", escrito de Ortí y Lara recogido en Jiménez Landi, op. cit., vol. I., "Apendices" (la frase citada en p. 382).

42. La versión más rigurosa y elaborada de la filosofía neotomista fue sin duda la elaborada por Zeferino González. En su obra se encuentra además una de las más exhaustivas críticas al krausismo. En relación con todo ello puede consultarse la tesis doctoral de Gustavo Bueno Sánchez, La obra filosófica de Fray Zeferino González. Universidad de Oviedo, 1991 (microforma). 
Tras el breve paréntesis revolucionario -en que estas voces se acallaron momentáneamente ante el apogeo del krausismo y su relativo control de ciertos resortes del poder-, y con el inicio de la Restauración, la crítica vino des de el campo conservador. Campoamor, en una serie de artículos publicados en la Revista Europea durante 1875 atacaría al "panentheísmo" polemizando con Francisco de Paula Canalejas. ${ }^{43}$ Desde una posición más radical, el padre F. Caminero (más tarde Obispo) tomaría el relevo de Ortí y Lara y dedicaría u na serie de artículos a la crítica de la doctrina de Tiberghien en materia religiosa y moral en la revista católica La defensa de la sociedad.44 Pero, sin duda, la crítica que iba adquirir mayor trascendencia, tanto por la categoría intelectual de su autor como por su tremendo arraigo en la cultura española posterior, vend ría de la mano de Menéndez Pelayo. En el volumen VI de su Historia de los heterodoxos españoles, el polígrafo montañés realiza una despiadada crítica del krausismo español y principalmente de su "creador", Sanz del Río. ${ }^{45}$ La dinámica elemental de todas estas polémicas era la siguiente. Por un lado, Ios detractores del krausismo se ocupaban, con independencia de su coincidencia con la realidad, de desacreditar el krausismo ante la sociedad acusándole de aquellos aspectos más susceptibles de ser considerados negativos por su auditorio: es por ello que les acusaban de formar una escuela, una secta oscurantista, una logía (en clara alusión a la masonería de Krause, pero no cierta en los más representativos krausistas españoles) etc. Menéndez Pelayo, en el lugar citado, Ilega a denominarlos "logia", "tribu", "cirulo de alumbrados", "fratria", "algo tenebroso y repugnante" y se refiere a las mencionadas tertulias de la calle Cañizares en las que Sanz del Río difundía el krausismo entre sus discípulos como un "conciliábulo pitagórico" que formaba por la noche "para ir catequizando a los estudiantes".

El otro pilar de la crítica de Menéndez Pelayo sería el de la ininteligibilidad de la filosofía krausista por su extravagancia terminológica y lo expone de manera muy gráfica:

“ ¡Si arrojáramos a la calle el contenido en un cajón de las letras de imprenta, de fijo que resultarían compuestas las obras inéditas de Sanz del Río". ${ }^{46}$

También les llamaban modernos, hombres del siglo, filósofos novísimos, extranjerizantes, germánicos, alemanescos..., a lo que añadían su falta de

43. Núms. 62, 63, 65, 67 y 73.

44. Bajo el título de "Estudios krausistas" entre 1875 y 1876 (núms. 124, 126, 142, 143 y 144). Ya antes, entre 1869 y 1870 había publicado el mismo autor cuatro artículos de similar naturaleza en la Revista de España (núms. 38, 39, 45, 48, 51 y 53) titulados "Examen crítico del krausismo" cuyo objetivo central era una vez más la filosofía de Tiberghien (lo cual muestra claramente la importancia del autor belga para el krausismo español).

45. Véanse especialmente las páginas 385-391 de la edición del CSIC de 1948.

46. Ib., p. 387. 
patriotismo; además les tildaban de panteístas (como el judío Spinoza), de falta de piedad, de irreligión y hasta de ateísmo:

"su panteísmo, visto de cerca, es ateísmo puro" ${ }^{47}$

No dejaban pasar la ocasión tampoco de relacionar su actividad política (republicana) con la anarquía, la subversión del orden y la revolución. Así, Campoamor describía la política krausista en la citada polémica sobre el panenteísmo del siguiente modo:

"política socialista, pues desde el baluarte del sistema armónico siempre están preparados, contra todo orden social cañones apuntados por artilleros cargados de buenas intenciones". ${ }^{48}$

La falsedad de la mayoría de estas críticas es flagrante de acuerdo con I a exposición de la filosofía de Krause y del krausismo que efectuamos en la primera parte de este trabajo, pero esa era una cuestión sin importancia en aqueIlas circunstancias: lo que contaba era echar por tierra, de la forma que fuese, el atractivo de la teoría krausista y con ello su creciente influjo en nuestra sociedad.

\section{III.1. La reacción legitimadora de los krausistas}

Semejante actitud provocaba inevitablemente una reacción defensiva en los krausistas, que negaban tales acusaciones creando ciertas ideas con fines legitimadores que desembocaron en una mezcla entre realidad e instrumentalización de la realidad por la que la historiografía pagaría un elevado precio. El hecho es que, para capear el temporal de críticas, los krausistas, con no menor sutilidad que sus detractores, se presentaron ante la sociedad no como ateos, sino como algo que continuaba la tradición española antes que algo completamente nuevo. De hecho, su pensamiento entroncaba con la mística española del siglo $\left.X V\right|^{49}$ y su filosofía no difería de la ortodoxia cristiana de los padre de la Iglesia: eran pues muy religiosos. El más avispado intento de la escuela krausista en este sentido fue la identificación llevada a cabo por Tiberghien entre el panenteísmo de Krause y la máxima de San Pablo "in deo sumus, vivimus et movemur"..$^{50} \mathrm{Si}$ ambos decían esencialmente lo mismo o la Iglesia atacaba su propia doctrina o Krause no podía ser calificado de panteísta.

47. J. M. Ortí y Lara, Krause..., op. cit., p. 21.

48. "iA la lenteja!, ¡A la lenteja!", en Revista Europea, núm. 65, p. 443.

49. Véase el artículo que F. de Paula Canalejas publicó en La Reforma en agosto de 1868 con el título de "Escuelas místicas españolas" (recogido en sus Estudios críticos de filosofía, política y literatura, Madrid, Baylli-Bailliere, 1872, pp. 317-79; resulta clave la pág. 378).

50. Cfr. Su Teoría de lo infinito. Madrid, 1872, p. 212. Ya Krause había afirmado que "vivimos, existimos y nos movemos en Dios" (Ciencia Pura Universal de la Razón o iniciación a la parte principal analítica de la estructura orgánica de la ciencia. Madrid, CSIC, 1989, p. 93, nota 22). 
Además les gustaba la paz y el orden, y, ante todo, no eran extranjerizantes: el Ideal de Sanz era más cosecha propia que traducción. Escuchemos lo que sus fideicomisarios dicen en la reedición de 1871:

"Aunque Sanz del Río atribuye modestamente el Ideal á Krause, dando á entender (-) es mera traducción del de este, hay entre su libro y el del filósofo alemán esenciales diferencias (a más de las que señalan sus notas y comentarios), tanto en el plan como en partes enteramente nuevas, que faltan en el segundo. Basta comparar los índices para convencerse de ello. El de Sanz del Río, si bien inspirado en la bella obra de Krause, es una exposición completamente libre de su sentido, acomodada al espíritu de nuestro pueblo y a las más apremiantes necesidades de su cultura. ${ }^{\text {s1 }}$

El culmen de este proceso de borrado de las huellas foráneas de la filosofía krausista que tan mal sentaban a sus detractores se encuentra en la Breve historia del krausismo español que un hombre afín al grupo, A. Posada, escribió hace poco más de medio siglo. Para el autor asturiano quedaba claro que el krausismo era una "planta netamente española". ${ }^{52}$

Tampoco en este caso la realidad podía sostener tales aseveraciones, pero no importaba.

\section{La historiografía sobre el krausismo: españolismo vs. universalismo}

Esta falsa dialéctica se prolongó en los años del franquismo porque se veía en la labor de la III República el culmen de la labor del krausismo, convenientemente diluida a través de la ILE. La versión Menendezpelayista fue la oficial del Régimen y, por tanto, la visión de los krausistas como antinacionales, liberales y masones -que habían deteriorado nuestra cultura-, imperaba. ${ }^{53}$ Desde fuera, autores como L. Araquistain, R. Llopis, J. Xirau, J. J. López Morillas etc. portaban el estandarte filokrausista con la versión del españolismo.

En los 60 les tocó el turno de recuperación historiográfica a los krausistas. ${ }^{54}$ En esos momentos fue determinante la labor de Pablo de Azcárate (sobrino de Gumersindo y por ello en poder del legado testamentario de Sanz del Río, del que Gumersindo había sido último fideicomisario) con numerosas publicaciones de material krausista en la editorial Tecnos, pero sobre todo con su impulso a un núcleo de investigación krausológica en torno al profesor J.L. Abe-

51. Op. cit., "Nota", incluida al frente de la obra por los mencionados fideicomisarios.

52. p. 23 (Edición de la Universidad de Oviedo de 1981).

53. Visión ejemplarmente recogida en la obra colectiva, Una poderosa fuerza secreta, La Institución Libre de Enseñanza. San Sebastián, Ed. Española S.A., 1940.

54. Cfr. E. Díaz, "Pensamiento político bajo el régimen franquista, 1939-1975", en Historia de la teoría política Madrid, Alianza, 1995. Vol. VI, pp. 509-548. 
Ilán, que se convertiría en el baluarte de nuestra historiografía sobre el tema. Formaron parte de ella hombres como E. Terrón o E.Díaz, primero, y F. Martín Buezas, A. Jiménez García o Teresa Rodríguez de Lecea, más tarde. ${ }^{55}$ Aunque algunos trabajos de gran valor como los de los profesores V. Cacho Viu o M. ${ }^{a}$ D. Gómez Molleda ${ }^{56}$ se hicieron al margen de esa corriente principal, fue ésta la que ha marcado las pautas básicas de nuestra historiografía krausista hasta finales de los años 80 . Durante este período la tendencia reaccionaria y antikrausista ha tenido en la figura de G. Fernández de la Mora su representante más activo. ${ }^{57}$

Pero a comienzos de esta década han dado sus frutos una serie de investigaciones comenzadas algunos años antes por un grupo de autores desde la Universidad Pontificia de Comillas (donde han fundado el "Instituto para el Estudio del Liberalismo, el Krausismo y la Masonería")..$^{58}$ La principal aportación del mismo ha sido el estudio exhaustivo de los orígenes alemanes del krausismo y el resultado más destacado la constatación de la identidad básica entre aquél y el desarrollado en nuestro país. Con ello toda la corriente del "españolismo", que únicamente había tenido en cuenta el krausismo español -fiándose de sus testimonios para establecer su originalidad con respecto a la filosofía alemana de Krause-, hace necesaria una revisión profunda de sus fundamentos. Obviamente, estos resultados no han sido fácilmente aceptados por sus trascendentales implicaciones para la interpretación vigente y su reflejo más inmediato es la polémica sostenida entre T. Rodríguez de Lecea por un lado y E.M. Ureña por otro. Áquella descalifica las investigaciones de este acusándolo de resucitar el pensamiento conservador en contra de Sanz del Río, ${ }^{59}$ pero lo cierto es que no aporta ningún argumento de peso, a parte de los supuestos prejuicios ideológicos de Ureña acerca de nuestro krausismo, mientras que Ureña ha dado mues-

55. Véanse las palabras del propio Abellán en su prólogo a la citada obra de T. Rodríguez de Lecea.

56. Los reformadores de la España Contemporánea. Madrid, CSIC, 1966. Trabajo que pese a su temprana elaboración incide con especial agudeza en los rasgos esenciales del movimiento krausista. Además de su reformismo, anunciado desde el mismo título, la autora destaca la importancia del "mito armónico" en el éxito krausista en un país dividido por las discordias internas (p. 52). Con ambas ideas estamos plenamente de acuerdo.

57. Es suficientemente representativo de esta postura su artículo "Krause en España", en Anales de la Real Academia de Ciencias Morales y Políticas, vol. 40, núm. 65, 1988, pp. 215-227.

58. Sus líneas principales, así como otras aportaciones diversas de primera magnitud han sido recientemente expuestas en el seminario sonre "La actualidad del krausismo en su contexto europeo", organizado en la Residencia de Estudiantes de Madrid por la Fundación Duques de Soria con la colaboración de la Universidad Libre de Bruselas, y cuyas Actas esperemos salgan pronto a la luz, dada la calidad de ponencias allí desarrolladas.

59. Además de su citado trabajo puede verse su reseña bibliográfica a la obra de López Morillas, Racionalismo pragmático. El pensamiento de Francisco Giner de los Ríos, que la autora claramente aprovecha para realizar una crítica de los trabajos de Ureña aparecidos por la mismas fechas. Cfr. BILE (2a época), núm. 7, 1989, pp. 113-116. 
tras documentales sólidas en apoyo de su teoría. La más contundente de el las es la publicación en un texto paralelo del ldeal de Sanz del Río -en el que supuestamente se comprobaba su originalidad y adaptación a España del krausismo- y ciertos artículos de Krause desconocidos hasta el momento y de los que el famoso ldeal es una traducción literal. ${ }^{60}$ Es lo que se ha conocido como "el fraude de Sanz del Río". 61

\section{IV.1. Evaluación del krausismo: la renovación cultural de España}

Así las cosas, es preciso poner fin a una polémica secular para afrontar con cierto distanciamiento desapasionado el krausismo español. Reconocer su escasa innovación con respecto a la filosofía idealista alemana de que procede, pero no para enjuiciarlo negativamente como mero plagio (cosa que nunca ha hecho Ureña), sino para tomar conciencia real de las cosas. Tampoco se debió su actitud a falta de patriotismo o extranjerismo. ${ }^{62}$ Esto se entiende perfectamente si tenemos en cuenta la famosa polémica sobre la ciencia española desatada entre G. de Azcárate y G. Laverde y que acabaría con la obra de Menéndez Pelayo sobre la cuestión. Azcárate -como los krausistas-consideraba que España había perdido comba en el progreso cultural europeo desde el siglo de Oro. Para enmendar este atraso, los krausistas estaban dispuestos a renovar nuestra cultura merced a la recepción del pensamiento que florecía entre nuestros vecinos más avanzados. Que eligieran o no el más adecuado o el potencialmente más progresista es algo secundario desde esta perspectiva y el debate sobre la conveniencia de Hegel sobre Krause no ha sido sino una de esas pistas falsas que surgieron con la dialéctica critica-defensa entablada entre los krausistas y sus detractores. El caso cierto es que mostraron una voluntad de abrir nuestro país a la moderna cultura europea. Y en este sentido su éxito fue rotundo porque no sólo favorecieron la entrada del resto del idealismo alemán (Schelling, Fichte y Hegel), del positivismo Comtiano, del criticismo neokantiano, del evolucionismo darwinista, de la sociología de Spencer o de la psicofísica de Fechner, sino que propiciaron el propio resurgir de la adormecida filosofía escolástica, que desenterró sus armas de combate para erigirse en alternativa al krausismo.

60. El "Ideal de la Humanidad" de Sanz del Río y su original alemán. Madrid, UPCO, 1992 (recientemente reeditado, 1997). Resulta especialmente interesante la "Introducción" del profesor Ureña que precede a la obra y en la que se explica en detalle tanto el paralelismo de los dos textos como las consecuencias del mismo.

61. Así comienza el título (que sigue "o la verdad sobre el Ideal de la Humanidad") del ya celebre (por sus enormes implicaciones para la historiografía sobre la materia) artículo de $\mathrm{E}$. $\mathrm{M}$. Ureña aparecido en la revista Pensamiento en 1988 (vol. 44, núm. 173, pp. 25-47).

62. Del patriotismo krausista ha dado justa cuenta el profesor Heredia Soriano en su artículo "El krausismo español y la cuestión nacional", en Enrahonar, 16, 1990, pp. 109-110, en especial. 
En el lado opuesto, los tradicionalistas consideraban la cultura española precedente como brillante y de ahí que fuera en ese modelo que tanto estimaban $-y$ no fuera de nuestras fronteras- donde encontraran el camino a seguir. EI resultado obvio de semejante actitud era la autarquía cultural y la vuelta al pasado en lugar de mirar al futuro. Sólo desde la disconformidad del krausismo con la propia realidad se podía realizar un esfuerzo adecuado para transformarla. Citarémos ahora unas palabras de Giner de los Río que creo que ilustran adecuadamente la polémica descrita. Por un lado rechaza:

"la censura que algunos de nuestros escritores han dictado en los últimos tiempos contra aquellos que, en el incipiente renacimiento de nuestra cultura científica, han vuelto los ojos hacia los filósofos extranjeros"

Y por otro arremete contra el nacionalismo cultural porque:

"es quimérico pensar que sin ayuda externa pueda la cultura española reponerse de su desmayo secular y alcanzar el nivel contemporáneo del Occidente Europeo. ${ }^{\prime \prime 3}$

Ese era su horizonte y queda clara, por tanto, la orientación europeísta del krausismo.

Hoy que ya no es negativo el europeísmo como actitud, sino al contrario, no es preciso mantener una estrategia legitimadora (y menos a costa de deformar la realidad histórica con la que cualquier investigación historiográfica que se pretenda seria debe ser extremadamente respetuosa) que la situación hizo necesaria como defensa de subsistencia, pero que hoy carece de sentido, se puede pues decir ya lo que fue, en verdad, el krausismo, lo cual dista tanto de ser esa bestia negra que nos describían los católicos radicales, como de la flor de nuestro pasado reciente que trataban de "vendernos" sus defensores. Como ya dijera P.Jobit hace más de medio siglo (cuando los ánimos estaban especialmente encrespados) en su pionero estudio, "el krausismo no merece ni ese exceso de honor, ni esa indignidad". ${ }^{64}$

Los juicios de valor pueden seguir emitiéndose, pero deben quedar al margen del trabajo historiográfico. Y nada mejor que traer a la memoria una vez más las palabras de Giner de los Ríos, indiscutible figura emblemática del pensamiento krausista, para cerrar este artículo. Las suyas, mejor que las nuestras, expresan el legado del krausismo español:

63. Citas tomada de J.J.López Morillas, Racionalismo pragmático. El pensamiento de Francisco Giner de los Ríos. Madrid, Alianza, 1988, p. 23.

64. Les éducateurs de l'Espagne contemporaine.T. I. Les krausistes. Paris, Ed. Du Broccard, 1936, p. 3. 
"Los 10 años del 60 al 70 -si cabe fijar límites tan arbitrarios- son un despertar de la vieja modorra al murmullo del moderno pensamiento europeo y a los problemas y nuevos postulados de su filosofía... Desde entonces, y a pesar de tantos esfuerzos en contrario, más o menos ininteligentes, pero enérgicos, y a veces sinceros, no ha sido posible ya contener las aguas de este pobre río, pobre y todo como es, de la atropellada cultura española." 65 
